\title{
ABSENT FRIENDS? THE GENDER DIMENSION IN INFORMATION SYSTEMS RESEARCH
}

\author{
Alison Adam \\ Debra Howcroft \\ Helen Richardson \\ Information Systems Research Centre \\ University of Salford \\ Salford M5 $4 W T$ \\ United Kingdom
}

\begin{abstract}
This paper argues that research on gender and information systems, from both quantitative and qualitative traditions, is problematic as the concept of gender continues to remain under-theorized. We discuss why this may have occurred given that an interest in gender has begun to permeate other disciplines. We elaborate an extensive critique of research which utilizes a statistical approach, discussing four recent papers with one MIS Quarterly paper taken as the cardinal example. We also include a shorter discussion of qualitative literature on gender and IS which reflects the paucity of published literature in this area. Here we see similar tendencies at work, where both gender and technology are taken to be fixed, "essential," and even stereotypical categories and where authors have yet to grasp the nettle of solidly theorizing the concept of gender against the extensive gender and information technology literature which now exists.
\end{abstract}

\section{INTRODUCTION}

The aim of this paper is to bring an added dimension, namely that of gender, to epistemological discussions in information systems (IS). We maintain that, in 
its attempts to argue the superiority of one epistemological position over another, the current debate threatens to obscure certain important political concerns within the IS arena. This is not an unknown idea in IS research. Indeed the editor-in-chief of MIS Quarterly, widely accepted as the discipline's flagship journal, recently commented: "I believe that authors can make their papers more likely to be compelling and significant if they additionally attend to the social and political dimensions of their craft" (Lee 1999, p. i).

This could be read as a volte-face, albeit a rather slow volte-face, from a journal which originally set the pace in the positivist, quantitative paradigm. However, this can also be read as a welcome step forward in a discipline where much of the literature still assumes an unproblematic, rational approach to management, organizations, and change, and involves mechanistic assumptions about organizational behavior (Bloomfield et al. 1997). If there is an avoidance of political concerns, this does not seem to be a deliberate action, but rather it is more a failure of nerve in apparently ducking some of the implications being raised when considering political questions. This is especially apparent with regard to gender research in IS. With this in mind, we choose to focus on this oft-neglected area here.

In particular, we will argue the significance of the fact that the concept of gender in IS research is largely under-theorized. Given that gender is just beginning to be considered as a serious research topic in IS, it is particularly important that we understand how the gender dimension is currently addressed, and what is problematic with its treatment. Within the limited space here, we make a beginning with a detailed analysis of recent research which illustrates a number of problems. We regard this scene setting as an important preliminary step before the possibility of undertaking further research which proffers a more extended framework for theorizing gender.

The argument that we present throughout this paper is based on the assumption that gender is a vital social factor shaping organizational life and thus it is inconceivable that the interaction of users with information systems is not in some way shaped by the "gendered" spheres we inhabit. We are not assuming "conspiracy" and seek to avoid dualism and dichotomies when considering gender and technology, since this offers little hope for a future way forward. Instead, we want to raise the question as to why things are the way they are, and not otherwise. In raising these issues we regard gender as a fundamental, indeed possibly the most fundamental, way of organizing and classifying our social experience. Therefore, understanding its classificatory and organizing powers should be read against the substantial tradition of research on ordering and classification which already exists (Bowker and Star 1999; Douglas 1984). As Suchman (1994a) points out, categories have politics. In particular, as 
feminist writing reveals, gender is a highly politically charged means of classification, as what is classified as "masculine" is often taken to be of higher status than what is regarded as "feminine" (Evans 1994). Within the present paper, we cannot possibly do justice to the many arguments of feminist writers on this topic. Nevertheless we hope that this brief discussion can serve to clarify what we mean by "gender" and can act as a pointer to some of the issues we discuss, e.g., the differential valuing of feminine and masculine attributes in the statistical studies described below.

The remainder of the paper is structured as follows. The next section considers, in more detail, the reasons why gender may have been undertheorized in IS research to date. Following this, we discuss the difficulties of finding published research on the topic of gender and IS, whether that be interpretivist or positivist in emphasis. In this section, we make it clear that we are focusing on particular styles of statistical research and qualitative research respectively. The next section analyzes research arising from the quantitative tradition, discussing four recent papers, with an MIS Quarterly paper taken as the cardinal example.

Our critique of statistical research in gender and IS is described under several categories. The first discusses the literature against which such research is couched and, in particular, the perils of ignoring existing gender and information technology research. The next section argues that focusing on a background literature of psychology places too much emphasis on individual gender characteristics, where a form of "essentialism" may creep in. This leads to a discussion of the way in which statistical studies of gender necessarily dichotomize male and female in searching for differences rather than looking at the ways in which particular roles and technologies may be seen as gendered. Next, we discuss the stereotypical characteristics that have been adopted in these statistical studies, in particular the way in which women's characteristics are often seen as having less value than men's. The next section argues that just as these studies tend to adopt a determinist position with regard to gender, so too do they adopt a determinist position with regard to the technology, tending to see it as fixed and inevitable in its introduction and use. Finally, we take issue with a number of recommendations made by the example papers as we argue that they further emphasize stereotypes, they patronize women, and reinforce workplace gender "ghettos." Our discussion of qualitative literature in gender and IS is, of necessity, shorter, reflecting the fact that there is even less published literature in this area. Nevertheless, we see similar tendencies at work where both gender and technology tend to be viewed as fixed entities not requiring analysis. In particular, we problematize the tendency of so many discussions on gender and IS which see the issue purely in economic "skills shortage" terms. 


\section{ACCOUNTING FOR THE UNDER-THEORIZATION OF GENDER IN IS RESEARCH}

We begin by asking the question, why is the issue of gender largely undertheorized, indeed neglected, in the IS literature?

One possible explanation could be provided by a cursory examination of the development of IS as a discipline. 'The field of IS is comparatively new, the first international conference in information systems (ICIS) took place in 1980 and the Association for Information Systems was established in the United States in 1994, with the UK Academy for Information Systems following one year on (Bacon and Fitzgerald 1996). The foundations of this emerging field are eclectic but it has arisen primarily as a reaction to the "technicism" (Lyytinen 1987) that is predominant in computing and engineering disciplines. Many academics are often placed in a minority position, aligned with a range of diverse disciplines, including computer science, management science, and organizational science (Culnan and Swanson 1986). Many of the disciplines from which IS has arisen have been primarily associated with the functionalist paradigm (Stowell and Mingers 1997) which focuses on the development and use of information systems in narrow technical terms, often disregarding their organizational context (Checkland and Holwell 1998). As a consequence, much time has been preoccupied with resisting technologically deterministic views of technology and by arguing for a recognition of the social, which would suggest that it offers much more scope for a richer theorizing of gender and other issues.

This reaction against functionalism has been coupled with a desire for intellectual respectability and the need to create a niche for IS as an emerging discipline. As a result, it is seen as essential that "proper" research topics be established. Within this endeavor to legitimize, the issue of gender has been neglected as a viable topic of study. What is particularly disappointing is that, when looking at the recent survey on the use of social theory in IFIP WG8.2 conference papers (Jones 2000), we see a noticeable absence of citations relating to social theory and gender studies. Jones notes that papers at these conferences generally cite social theorists far more frequently than is typical in the IS field as a whole and in this respect the conference could be placed in the "vanguard of the IS field" (p. 15). Yet there is little evidence here to indicate either a "cumulative tradition" or "faddish fluctuation of interests" relating to social theory and gender.

${ }^{1}$ This in itself is problematic and subject to much debate. However, it is not our intention here to either define the discipline or indeed debate its very existence. We simply use the notion of IS as an emerging discipline as a vehicle to help understand the paucity of gender-related research. 
Yet, somewhat ironically, while IS has largely ignored gender issues, the discipline of computing has chosen to take issue with the poor representation of women in the IT field (Grundy 1996; Lovegrove and Segal 1990). We can only hypothesize that the reason why computing seems prepared to entertain a gender, or at least "women's," dimension is that it is not seen to threaten the core of computing -it can be kept at arm's length as it is not seen as a technical concern and, therefore, poses no threat to the discipline's center. However IS, with its pretensions toward social and organizational research, is in a different category. Any claims regarding gender are claims about how we organize our social, political, and organizational existence and are potentially more threatening to the core of IS than to the center of the computing discipline. Consequently, this adds to the dearth of research on gender and IS. Hence, we create a self-fulfilling prophecy, as the tacit lack of legitimacy of gender and IS as a research topic results in little or no attempt to progress the area and it then becomes viewed as a topic unworthy of publication and projects.

Over time, as IS became more established and received stronger recognition as a discipline in its own right, neglected issues began to emerge and these are now considered worthy of study. For example, the very shift from the predominance of positivism to increasing engagement with interpretive approaches can be seen as part of the process of an increasing confidence in the discipline and a willingness to take on board broader issues (Klein and Myers 1999; Lee et al. 1997). Unfortunately for the IS field, the topic of gender is starting to surface during a period that has been described by some as "post-feminism," or what Faludi (1992) denotes as a "backlash" whereby gender studies are seen far less favorably as it is assumed that the "battles" have all been won and those who argue differently may be seen as whingeing. We would strongly argue against this so-called backlash, since we maintain that the issue of gender and IS needs to be adequately addressed if the field is to make further progress in this important direction.

\section{QUANTITATIVE AND QUALITATIVE APPROACHES TO GENDER AND IS}

In the following sections, we analyze both qualitative and quantitative research that focuses on gender and IS. Interestingly, though not surprisingly given the considerations above, we found very few papers on gender that were located unequivocally within the IS literature. Had we allowed ourselves to dip into the women and computing literature, or the management science literature, we would have found many more. In our survey of relevant literature, we are not attempting to be comprehensive; rather the intention is to focus on material 
which can be seen as published in specifically IS outlets and which is representative of the slender literature that exists.

In the quantitative tradition, we have included four papers which are representative of a very sparse collection of papers studying gender and IS that use statistical methods. However a qualitative gender and IS research tradition appears to be almost non-existent. Again, staying with journals and conferences explicitly within the IS field, there are a few isolated papers such as Suchman's (1994c) study of feminist epistemology and politics in working relations of technology production and use and Wilson and Howcroft's (2000) study of gender and user resistance. There is also some evidence that authors, well known in the IS world, save their research on gender for a more feminist audience where they may get a more sympathetic hearing (Suchman 1994b; Star 1991). For the present discussion, we report on three qualitative papers, two of which are published in mainstream IS journals (Harvey 1997; Panteli et al. 1999) and the other in conference proceedings (Robertson et al. 1999). We return to this qualitative research after an analysis of the quantitative papers.

\section{QUANTITATIVE APPROACHES TO GENDER AND IS}

In this section, we base our analysis around three papers published in MIS Quarterly in 1994, 1997, and 2000, respectively, and one paper from Information Technology and People. The MIS Quarterly papers we regard as being of special significance since they are the only papers focusing specifically on gender within MIS Quarterly, which is widely taken as the discipline's most authoritative journal (Hardgrave and Walstrom 1997). Therefore, we are treating these papers as representative of the "state of the art" of gender research in mainstream IS. For reasons of space, our discussion will center around the most recent of these papers, viz. Venkatesh and Morris's (2000) survey of technology acceptance, alluding to the others where appropriate to explicate details of the argument, since they all adopt a similar methodological approach.

All four papers report statistical analyses of detailed empirical surveys of men and women in the workplace. Hence, they are located firmly in the quantitative tradition: for the MIS Quarterly papers this is hardly surprising given the journal has only recently softened its stance toward more qualitative research. But, it is not with the quantitative approach, as such, that we take issue as we recognize that there are many types of quantitative research. We argue it is rather the style of explanation that is problematic in these papers. In a nutshell, this research has difficulty explaining the phenomena it apparently uncovers as it does not adequately theorize the construct of gender, nor indeed 
the construct of technology. Neither concept is fixed or immutable. As we discuss below, both require theorizing. This needs to be done against the burgeoning literature on gender and technology (and, more specifically, gender and information technology), a growing body of literature which has not been substantially cited in any of the papers discussed in this section and which two completely avoid. To be fair, this is not to argue that they do not couch themselves against some relevant framework of literature which discusses gender in some form or other. However, for reasons that will be discussed below, we will argue that these are either inappropriate or insufficient for offering the required degree of explanatory power. Furthermore, the maximum explanatory power is not being extracted from the literature that is used and is, therefore, not providing the required degree of gender theorizing and technology theorizing that is needed to make sense of the results obtained and to draw out their full political implications. In particular, as we describe below, there are difficulties with the statistical methods used as we believe that this forces the concept of gender into a dichotomous tension between masculine and feminine.

Venkatesh and Morris's research addresses gender differences in the context of individual adoption and continued usage of information technologies in a longitudinal (five months) questionnaire based study. Their research question was: "Are men and women different with respect to technology adoption?" (p. 128).

In studying user reactions and usage behavior among 342 workers being introduced to a new software system, they found that men's technology usage decisions were strongly influenced by their perceptions of usefulness (PU), while women were more strongly influenced by perceptions of ease of use (PEOU) and subjective norm (i.e., whether others influence one's behavior). In this research, the authors were seeking to extend Davis's (1989) original and, by now, extensively applied technology acceptance model (TAM) to include gender and social influence. Gefen and Straub (1997) also seek to extend the TAM model in relation to a study of gender differences in the perception and use of e-mail. They obtained 392 questionnaires from "knowledge workers" based in three international airlines. Truman and Baroudi's (1994) study focuses on possible gender discrimination in senior ranks of the IS profession. A postal survey was conducted through the Society for Information Management (SIM), targeting IS executives from manager to CEO.

Our analysis is made against the following categories: the literature tradition within which the research is located and the problems that arise from ignoring recent gender and technology research; the problem of men's and women's essential psychological characteristics; the way in which statistical analysis dichotomizes gender; how such an analysis is used to predict and affirm various aspects of technology acceptance; and finally, how technological determinism 
tends to permeate the research, hand-in-hand with gender determinism. It is against these arguments that we analyze the claims made in the four papers using Venkatesh and Morris's paper as the most recent and, therefore, most representative.

\subsection{Gender and IS: Which Literature?}

Venkatesh and Morris's reference list reveals the locus of their research. The works referenced belong to the literature of behavior and psychologysocial, organizational, and educational - with many references to quantitative, psychology-based studies in the IS literature. All gender references derive from psychology literature and there are no references to gender and technology literature. From the latter domain, the best known and most widely referenced research in gender and technology includes Wajcman's (1991) Feminism Confronts Technology and Cockburn's (1985; Cockburn and Ormrod 1993) studies in the 1980s and 1990s. There is also a flourishing series of IFIP 9.1 conferences on Women, Work and Computerization (Adam et al. 1994; Balka and Smith 2000; Grundy et al. 1997; Tijdens et al. 1991) containing much potentially relevant material; with the IFIP banner this is as near to the mainstream that research on gender and information technologies can be. As the dates reveal, much of this material has been widely available for some years. We acknowledge that these references are not part of the IS literature, as such. However, given the interdisciplinary nature of IS, and given that any researcher explicitly searching for purely gender and IS references will turn up very few, there is a pressing rationale to look outside the immediate domain of IS. Under the circumstances, it is quite surprising that this material is not referenced.

Ignoring the existing gender and technology literature and concentrating on citations from psychology makes the whole process of technology acceptance and usage appear more a product of individual psychology obviating the need to consider the social structures within which individuals necessarily operate. This also obscures inequalities in power relations. Technology acceptance is not necessarily the choice of a freely operating individual. The men and women in the study may not have had the same choice as to whether or not they accepted the particular software system as their jobs may have been quite different. If, as is traditionally the case, the men were higher up the organizational hierarchy, their working lives may well have been quite different in both content and focus. To say that one is statistically controlling for income, occupation, and educational levels is not the same as examining and understanding the rich and structured picture of men's and women's working lives and also their history of technology use and acceptance. 
For instance, Panteli et al.'s $(1999$, p. 117) study of women in the UK information technology (IT) industry found that despite women's pay being consistently lower than men's, women in the IT industry display similar aspirations to men, with a significant proportion of women rating responsibility, interest, and challenge in their working lives even higher in importance than their male colleagues. The type of richness and complexity of experience revealed in this study cannot be captured in a study which sees job title and salary as statistical variables that can be controlled and accounted for in making comparisons of men's and women's experiences of work.

\subsection{Psychological Gender Characteristics: Essentialism in Disguise}

The findings of Venkatesh and Morris's study reveal that men emphasized perceived usefulness (PU) while women emphasized perceived ease of use (PEOU) in their attitude toward the introduction of a new software system. These differences they explain by reference to psychological distinctions between men and women garnered from the literature. There are two problems with this. First, all the psychological characteristics are in danger of becoming seen as "essential" aspects of men's and women's characters; this is explained below. Second, the chain of reasoning from an "essential" gendered characteristic to the prediction of some aspect of technology acceptance could be made quite differently if the more socially structured gender and technology research literature is taken into account. We will illustrate this in relation to the paper's hypothesis and findings regarding men and $\mathrm{PU}$, in characterizing it in terms of a productivity-oriented factor.

The tendency to essentialize gender characteristics makes men's and women's characters and behavior seem fixed and pre-determined, reproducing and reinforcing well-known stereotypes. This can be seen as a form of gender determinism. Balanced against this is a technological determinism which we discuss in a later section. Much writing on gender analysis in recent years has focused on the problem of essentialism (Kirby 1991). Essentialism is the belief that there are essential, fixed, probably biological, male and female characteristics. Trying to pin down essential masculine and feminine characteristics seems a futile, and probably impossible, pursuit. What is more important is that the characteristics associated with men (whether they are found by psychological research or whatever) are usually valued more in society than characteristics associated with women. This is often crystallized in the workplace where "female" occupations such as secretary or personal assistant are paid less than "male" occupations such as manager. 
Essentialism has reared its head in relation to gender and technology in the assumption, made by many early writers in the field, that women's relative absence from the technological domain could be understood in terms of some essential differences in the way men and women relate to the world (Ruddick 1989). Grint and Woolgar (1995) claim that early writing on feminism and technology replaced technological determinism with an equally problematic social determinism. Instead, they argue that what counts as masculine or feminine in relation to technology lies in the interpretations made of masculinity and femininity and not in the technology itself. Although this is an epistemologically relativist position, they believe it offers a more liberating potential for women rather than realist positions, which have often proved oppressive.

\subsection{Dichotomizing Gender: A Problem of Statistics}

All four studies utilize statistical techniques where population samples are surveyed and gender is seen as a dichotomous variable, where specific differences in the genders are looked for and where corresponding hypotheses are of the broad form: women will do some behavior less or more than men do the same behavior. We argue that this style of statistical analysis forces gender into polarized masculine and feminine categories, therefore emphasizing differences between the two. It has the further effect of making male and female appear as autonomous categories, de-emphasizing the effects of age, class, and ethnicity. It also promotes discussion about "essential" or intrinsic male and female characteristics, as described above, and how these are reflected in attitude to technology acceptance or work.

\subsection{Male Characteristics vs. Female Characteristics}

Venkatesh and Morris look to research on gender differences in the salience of outcomes as determinants of behavior. These include the following (pp. 117118): men's work role is typically their most salient while family role is often only of secondary importance; men place greater emphasis on work, accomplishment, achievement, eminence, are more focused on individualistic tasks and goals, value traits that are "objective" and "logical," are more assertive than women, rate advancement and earning power more highly than women do. By contrast, the relevant characteristics of women are given as follows (pp. 119120): tenderness, expressive, motivated by affiliation, prefer person-oriented professions, motivated toward success in personal relationships, more concerned with pleasing others and maintaining a harmonious environment. Women are seen as more compliant and more likely to conform to majority opinion than are men. 
We note a number of interesting features about these lists of characteristics. All but one of the references describing male and female characteristics respectively hail from the 1970s and 1980s. This strongly suggests that the authors are missing a later literature which may have offered different findings (although admittedly they do acknowledge that some of these findings may be dated [p. 120]). We have already argued that the substantial literature on gender and technology is certainly missing. However, it is also noteworthy that in the paper, no distinction is made between psychological findings in relation to women and men in general, and women and men specifically in the workplace. This means that the authors cannot know whether the apparently sharp psychological distinctions between men and women in general and which they rely on in their arguments are relevant in a world where women make up a considerably larger fraction of the workforce than when many of the original reference studies were conducted. It is conceivable that the psychological traits of women in the workplace may differ from those whose role is outside the paid workforce. As we have already noted, Panteli et al. found that, contrary to stereotypes, the women in their workplace studies were more focused on achievement and work than were many of the men.

There is also evidence that male characteristics are treated more positively than female characteristics, as we have previously described. The words associated with men include achievement, eminence, accomplishment, advancement, logical, objective, assertive. While the terms describing women are not necessarily negative, they do not have the same "high flying" connotations and sit uncomfortably with the vocabulary of achievement associated with men. It is hard to escape the conclusion that Venkatesh and Morris are falling prey to stereotypical gender characteristics which, while rooted to some extent in the psychology literature, are nonetheless associated with studies which predate more recent research on women in the workplace (Webster 1996) and gender and technology (Wajcman 2000), which mount a substantial challenge to such stereotypes.

We see a very similar process at work in Igbaria and Chidambaram's (1997) paper on the impact of gender on career success of information systems professionals. These authors examine career success in terms of human capital, i.e., the theory that people invest in themselves in various ways, not just for immediate enjoyment but for various returns, financial or otherwise, in the future. We note that the background literature of this paper is clearly different from Venkatesh and Morris's, but similarly, most references are pre-1990 and, once again, the gender and technology literature is not referenced, including, importantly, no mention of Webster's highly relevant study of men and women in IT employment.

However, the main aspect of Igbaria and Chidambaram's paper with which we wish to take issue here is the way that their approach holds women up to a "male as norm" and finds women wanting. Indeed the balance is even more stark 
in the human capital paper than in Venkatesh and Morris's research. For instance, the paper regards women's generally poorer position in the IS career market in terms of the human capital paradigm which sees women as accumulating "lower education levels, less experience and fewer skills, particularly in professional and managerial areas" (Igbaria and Chidambaram 1997, p. 65). It suggests further that women choose to invest less in human capital if they anticipate a lower return on their investment due to career interruptions. No point in digging deep into one's pocket for that costly MBA program if one is going to be stuck at home with the kids in a few years time!

Further, it implies women have higher turnover rates, more career interruptions and less success because they have fewer skills, less experience, lower education levels, less work-specific training and because they give higher priority to family responsibilities (Igbaria and Chidambaram 1997, p. 66).

Human capital theory sees all these as voluntary choices. Igbaria and Chidambaram do point out that some of the literature on human capital discusses the way that human capital investment does not work in favor of women and some minorities as well as it tends to do for white men. This suggests that there are also discriminatory practices at work. However, Igbaria and Chidambaram do not regard this as a reason to abandon or modify human capital theory. Rather they prefer to see a mixture of human capital formation and discrimination as at work in women's careers. Nevertheless, the rest of the paper tends to lose sight of the forces of discrimination, which is, in any case, a crude and broad brush term for the more subtle differentials of power and the gendering of roles, in other words a more theoretically informed model of gender. The problem, then, is that the human capital model used here measures women against men and finds them wanting on almost all counts. It is the "language of less"-women have less of this and less of that-always against a supposed male standard.

Even accounting for all the differences in human capital parameters, women still fare less well than men in terms of job grade and salary. But Igbaria and Chidambaram's theoretical perspective gives them little scope for grasping that particular nettle or for giving a convincing explanation other than suggesting women are not as good as men at networking, for which they present no evidence. They suggest that we need to look to psychology for explanations and that employers just need to "try harder" when it comes to inequalities of salary.

Truman and Baroudi's study of potentially discriminatory factors in the IS profession takes a similar approach to that of Igbaria and Chidambaram, although it is not so tightly linked to the human capital literature. They propose: "The prevailing consensus has cast the IS occupation as relatively immune from 
the serious discrimination patterns found in most other occupations"(Igbaria and Chidambaram 1997, p. 129). They make no literature reference to support this claim. If this is (or was) a widespread feeling in the IS domain, then it is not clear where this came from or indeed whether that feeling still reflects the mood of the profession. Our only suggestion is that claims may be made that new professions, having no long history of discrimination, may be held up as paragons of equality, that is until studies come along which may show otherwise. There is no evidence to support such an assertion.

Truman and Baroudi are also reluctant to get to grips with the concept of potential discrimination in order to theorize and explore what that might mean. Instead, to help explain results which similarly show men in a better position in the IS profession, they argue, again without any actual evidence: "It is quite possible that women opt out of the profession as they reach a certain age to assume primary family care responsibilities" (Truman and Baroudi 1994, p. 138).

In the face of an extended statistical study, it is disappointing to see women being held to a negative stereotype against masculine behavior, particularly when no evidence is adduced to support it.

\section{PREDICTING GENDERED BEHAVIOR IN IS}

Our second concern with gender characteristics relates to how these are used to predict and affirm various aspects of technology acceptance. Venkatesh and Morris's (2000) main claim is that men are more influenced by perceived usefulness (PU) and women more by perceived ease of use (PEOU) and social norm in the acceptance of technology. We examine the first claim here. Venkatesh and Morris (p. 118) argue that because men are more motivated by achievement needs, they are more focused on accomplishing individualistic tasks and goals than women and, therefore, they expect productivity enhancement to be more salient for men.

There appears to be a non sequitur here. It is not at all clear that status, achievement, and eminence are necessarily linked to productivity. Given the set of masculine attributes used by Venkatesh and Morris, we believe that a more convincing hypothesis would be that factors more specifically related to status enhancement would be more salient for men. That this is a more convincing argument is shown, not only by the way it fits in with Venkatesh and Morris's original set of male psychological characteristics, but also by the way it relates to arguments from the gender and technology literature, which shows that technology is often a potent source of status for men (Cockburn 1985; Wajcman 1991, 2000). 


\subsection{Technological Determinism}

As we have argued above, because gender tends to be seen as a fixed and immutable category, so too may technology be seen as fixed, immutable, and inevitable. We know nothing of the politics, practice and functionality of the introduction of the software system in Venkatesh and Morris's study. Did it replace an older system which was used by some grades of staff but not others? Who had a "say" in the choice and introduction of the system? The hidden power differential is bound to make a difference to perceptions as to the acceptance of a software system, yet it is conveniently sanitized out of the story under the aegis of statistical control. This amounts to a form of technological determinism, a subject of much debate in science and technology studies in the 1980s (MacKenzie and Wajcman 1985). Whereas arguments as to the pitfalls of technological determinism have permeated into the interpretivist end of IS perhaps, not surprisingly, they leave no mark on more quantitatively inspired IS research. Both gender and technology need to be problematized, to be seen as cultural products rather than as "givens" if they are to avoid both forms of determinism.

\section{ANALYZING THE RECOMMENDATIONS FROM QUANTITATIVE RESEARCH}

Finally, in the light of the preceding arguments, we take issue with a number of the recommendations made in the papers discussed under the quantitative banner. At best, the recommendations can seem weak, e.g., little more than a call for the IS industry to do better in terms of potentially discriminatory practices; at worst, some recommendations can be seen as reinforcing the dichotomy between male and female and buttressing negative gender stereotypes.

Truman and Baroudi's (1994) recommendation that organizations attend to their potentially discriminatory practices belongs to the latter category. Interestingly, they relate this recommendation explicitly to the idea that the labor pool will shrink significantly if employers do not take heed, rather than a will to promote fairness and equality. Gefen and Straub (1997, p. 391) look to similar economic arguments to promote the gender balance, rather than an argument couched in the language of fairness. Such arguments are not confined to the quantitative literature but rhetoric more generally used in the teeth of continuing skills shortages in IT.

The problem of reinforcing gender stereotypes is raised by Venkatesh and Morris's (2000) recommendations that technology trainers should tailor their training programs according to the gender of participants in relation to their 
findings on gender and technology acceptance. Similarly, in the conclusion to their e-mail study, Gefen and Straub (1997, p. 398) recommend that IT trainers should emphasize feelings, thoughts and user-friendliness in training women.

We find recommendations such as these particularly worrying. There is some evidence to suggest that women in single sex groups fare better than those in mixed groups in relation to IT education (Nightingale et al. 1997). However the separate styles of training for women suggested in these papers are based on a set of stereotypes which we have already argued tend to see women in a lesser role than men. In addition, because they are stereotypes, they pander to a "touchy-feely" view of femininity which may well make women feel patronized and can contribute to further gender segregation and the maintenance of ghettos in the workplace. This area clearly needs further research.

\section{QUALITATIVE RESEARCH ON GENDER AND IS}

As a less well developed tradition in IS literature, there are currently fewer points for analysis in qualitative research on gender in IS. Nevertheless, we reiterate our contention that this research, in the same way as quantitative research, must develop a tradition of explicitly theorizing gender, looking toward the gender and technology literature in the process. Robertson et al.'s (1999) conference panel discussion raises many important issues in terms of the absence of women in IS, the importance of gendered relations, including informal networks and theoretical issues of power. However, it would be fair to say that the authors see their paper as part of an ongoing discussion rather than something which should be taken as a substantial piece of research.

Harvey's (1997) paper on gendered genres in IT cultures uses a Foucauldian analysis of ethnographic fieldwork to study formative cultures that have influenced IT culture and is particularly welcome as she consciously reflects on her own experiences. Although this is probably the most theoretically informed paper on gender that we have so far found in the IS literature, we note that it makes almost no reference to the gender and IT literature we describe above. Although many women (and men) will relate to her descriptions of "genitaliaspeak" in working contexts and how such language is used to affirm membership of the dominant culture and to exclude women, categories of what counts as masculine and feminine are taken for granted and not sufficiently analyzed in the paper. Indeed as the paper relies heavily on the power of language, the substantial literature on gender and language (e.g., see Cameron 1998) would also have been useful in developing theoretical aspects of gender. In taking what counts as gender for granted, Harvey is also in danger of taking IT for granted as the studies are centered around masculine culture in the workplace in general, where the link to the technology becomes somewhat tenuous. This echoes Wajcman's 
(2000) plea that we must treat both gender and technology as cultural variables to be analyzed and explained.

Although qualitative research does not tend to dichotomize gender in the style of the statistical approach, so far, much of the energy of qualitative gender and IS writing is expended on the problem of the low numbers of women in the IS profession and women's low status within it; indeed this is the explicit focus of Panteli et al.'s (1999) study. This paper has a quantitative aspect in that it is a discussion of secondary research reporting percentages and averages relating to women's and men's positions in the UK software industry. The original empirical research of the paper is based on a set of case studies. Therefore, we believe it is fair to treat the paper as hailing from a different tradition than the four quantitative papers we discuss above. We agree that this is a serious and ongoing issue which continues to require a search for satisfactory measures. It also mirrors the continuing discussion in computing and other technical disciplines. However, as discussed above in relation to Gefen and Straub's (1997) study, there are problems in treating women's absence from IS as an economic matter connected purely with skills shortages. Even if there were no skills shortages, women's unequal position in IS would still have to be addressed.

Our conclusion in regard to qualitative research on gender and IS must be that there is such a paucity of research that the field is (almost) wide open. While we acknowledge continuing problems of low numbers and status of women in IS, our hope is that the field does not become dominated by old liberal arguments about getting women into a discipline which is perceived as inherently neutral since this will simply mirror the problems of gender and technological determinism already noted in relation to quantitative research studies. Similarly there is just as much a requirement for qualitative research to take seriously the call for a thorough theorizing of gender and technology as cultural phenomena.

\section{CONCLUSION}

When engaging with the debate concerning the nature of the IS discipline, Jones (1997) makes the point that: "IS researchers should seek to do research which is good in terms of other disciplines" (p. 107) and that is comparable, in terms of standards, with the discipline on which it is based. He notes that this is no easy task and, indeed, is certainly no guarantee of acceptance, particularly given the resistance of mainstream studies to new perspectives. This is not to say we should be overly pessimistic when presenting research that questions the orthodoxy. On the contrary, we should seek to engage with others and have confidence in the validity of our argument, assuming that over time they too will acknowledge its importance. 
In the above discussion, we have sought to make detailed criticisms of statistical research on gender and IS and more qualitatively inspired writing on gender and IS. There are a number of aspects to this but we are particularly critical of the way that such research necessarily sees gender as a dichotomy against which differences are measured. This has the effect of making it seem as though men and women have fixed "essential" characteristics where women's characteristics are in some ways seen as less positive than men's. An implicit technological determinism goes hand-in-hand with this form of social determinism. Although qualitative research on gender and IS is a less developed field, it is not immune to essentialism.

Our approach has been critical of existing research but this is done in the spirit of seeking a positive way forward. As we have suggested, this is seen in terms of a more explicit theorizing of gender and of technology, preferably in the manner of existing gender and technology research. We see, for example, Cockburn and Ormrod's (1993) groundbreaking study of the development of the microwave, which couched an empirical study in solid theorizing about the way that gender relations were inscribed in microwave oven technology, as a paradigm example. Finally, what we have to say here relates to inequalities generally, including class and race, and although we focus specifically on gender, we would encourage investigation of other similarly neglected issues.

\section{REFERENCES}

Adam, A., Emms, J., Green, E., and Owen, J. (eds.). Women, Work and Computerization: Breaking Old Boundaries-Building New Forms, Amsterdam: Elsevier/North-Holland, 1994.

Bacon, J., and Fitzgerald, B. "The Field of IST: A Name, a Framework, and a Central Focus," Executive Systems Research Centre Working Paper Series, University College Cork, 1996.

Balka, E., and Smith, R. (eds.). Women, Work and Computerization: Charting a Course to the Future, Boston: Kluwer, 2000.

Bloomfield, B. P., Coombs, R., Knights, D., and Littler, D. Information Technology and Organizations: Strategies, Networks, and Integration, Oxford: Oxford University Press, 1997.

Bowker, G. C., and Star, S. L. Sorting Things Out: Classification and Its Consequences, Cambridge, MA: MIT Press, 1999.

Cameron, D. (ed.). The Feminist Critique of Language: A Reader ( $2^{\text {nd }}$ Edition), London: Routledge, 1998.

Checkland, P., and Holwell, S. Information, Systems and Information Systems, Chichester, England: John Wiley and Sons, 1998.

Cockburn, C. Machinery of Dominance: Women, Men and Technical Know-How, London: Pluto Press, 1985.

Cockburn, C., and Ormrod, S. Gender and Technology in the Making, London: Sage, 1993.

Culnan, M., and Swanson, E. B. "Research in Management Information Systems 1980-1984: Points of Work and Reference," MIS Quarterly (10:3), 1986, pp. 289-301.

Davis, F. "Perceived Usefulness, Perceived Ease of Use, and User Acceptance of Information Technology," MIS Quarterly (13:3), 1989, pp. 319-339. 
Douglas, M. Purity and Danger: An Analysis of the Concepts of Pollution and Taboo, London: Routledge and Kegan Paul, 1984.

Evans, M. (ed.). The Woman Question, London: Sage, 1994.

Faludi, S. Backlash: The Undeclared War Against Women, London: Vintage, 1992.

Gefen, D., and Straub, D. "Gender Differences in the Perception and Use of E-mail: An Extension to the Technology Acceptance Model," MIS Quarterly (21:4), 1997, pp. 389-400.

Grint, K., and Woolgar, S. "On Some Failures of Nerve in Constructivist and Feminist Analyses of Technology," in The Gender-Technology Relation: Contemporary Theory and Research, K. Grint, and R. Gill (eds.), London: Taylor and Francis, 1995, pp. 48-75.

Grundy, F. Women and Computers, Exeter, England: Intellect, 1996.

Grundy, F., Kohler, D., Oechtering, V., and Petersen, U. (eds.). Women, Work and Computerization: Spinning a Web from Past to Future, Berlin: Springer-Verlag, 1997.

Hardgrave, W., and Walstrom, K. "Forums for MIS Scholars," Communications of the ACM (40:11), 1997, pp. 119-124.

Harvey, L. "A Genealogical Exploration of Gendered Genres in IT Cultures," Information Systems Journal (7), 1997, pp. 153-172.

Igbaria, M., and Chidambaram, M. "The Impact of Gender on Career Success of Information Systems Professionals," Information Technology and People (10:1), 1997, pp. 63-86.

Jones, M. "It All Depends What You Mean by Discipline...," in Information Systems: An Emerging Discipline?, J. Mingers and F. Stowell (eds.), London: McGraw-Hill, 1997, pp. $97-112$.

Jones, M. "The Moving Finger: The Use of Social Theory in WG 8.2 Conference Papers, 19751999," in Organizational and Social Perspectives on Information Technology, R. Baskerville, J. Stage, and J. I. DeGross (eds.), Boston: Kluwer Academic Publishers, 2000, pp. 15-31.

Kirby, V. "Corporeal Habits: Addressing Essentialism Differently," Hypatia (6), 1991, pp. 4-24.

Klein, H. K., and Myers, M. D. "A Set of Principles for Conducting and Evaluating Interpretive Field Studies in Information Systems," MIS Quarterly (23:1), 1999, pp. 67-94.

Lee, A. "Editor's Comments: Strategizing for Compelling and Significant Research," MIS Quarterly (23:2), 1999.

Lee, A. S., Liebenau, J., and DeGross, J. I. Information Systems and Qualitative Research, London: Chapman \& Hall, 1997.

Lovegrove, G., and Segal, B. Women into Computing: Selected Papers 1988-1990, London: Springer-Verlag, 1990.

Lyytinen, K. "Different Perspectives on Information Systems: Problems and Solutions," $A C M$ Computing Surveys (19), 1987, pp. 5-46.

MacKenzie, D., and Wajcman, J. (eds.). The Social Shaping of Technology, Milton Keynes, England: Open University Press, 1985.

Nightingale, W., Halkett, A., and Hammond, K. "Involve: Inclusive Teaching in First Year Computer Science Courses," in Women in Computing, R. Lander and A. Adam(eds.), Exeter, England: Intellect, 1997, pp. 154-159.

Panteli, A., Stack, J., Atkinson, M., and Ramsay, H. "The Status of Women in the UK IT Industry: An Empirical Study," European Journal of Information Systems (8), 1999, pp. 170-182.

Robertson, M., Bjerknes, G., Mathiassen, L., Newell, S., and Swan, J. "is Gender an Issue in Information Systems? A Comparative Analysis of UK and Scandinavian Data and Experience," in Proceedings of the Seventh European Conference on Information Systems, J. Pries-Heje, C. Ciborra, K. Kautz, J. Valor, E. Christiannse, D. Avison, and C. Heje (eds.), Copenhagen, 1999, pp 1032-1037.

Ruddick, S. Maternal Thinking: Toward a Politics of Peace, Boston: Beacon, 1989.

Star, S. L. "Invisible Work and Silenced Dialogues in Knowledge Representation," in Women, Work and Computerization: Understanding and Overcoming Bias in Work and Education, 
K. Tijdens, B. Kitchenham, and I. Eriksson (eds.), Amsterdam: North-Holland, 1991, pp. 8192.

Stowell, F., and Mingers, J. "Information Systems: An Emerging Discipline?" introduction to in Information Systems: An Emerging Discipline?, J. Mingers and F. Stowell (eds.), London: McGraw-Hill, 1997, pp. 1-15.

Suchman, L. "Do Categories Have Politics? The Language/Action Perspective Reconsidered," Computer Supported Cooperative Work (2), 1994a, pp. 177-190.

Suchman, L. "Supporting Articulation Work: Aspects of a Feminist Practice of Technology," in Women, Work and Computerization: Breaking Old Boundaries-Building New Forms, A. Adam, J. Emms, E. Green, and J. Owen (eds.), Amsterdam: Elsevier/North-Holland, 1994b, pp. 7-21.

Suchman, L. "Working Relations of Technology Production and Use," Computer Supported Cooperative Work (2), 1994c, pp. 21-39.

Tijdens, K., Kitchenham, B., and Eriksson, I. (eds.). Women, Work and Computerization: Understanding and Overcoming Bias in Work and Education, Amsterdam: North-Holland, 1991.

Truman, G. E., and Baroudi, J. J. "Gender Differences in the Information Systems Managerial Ranks: An Assessment of Potential Discriminatory Practices," MIS Quarterly (18:2), 1994, pp. 129-141.

Venkatesh, V., and Morris, M. "Why Don't Men Ever Stop to Ask for Directions? Gender, Social Influence, and Their Role in Technology Acceptance and Usage Behavior," MIS Quarterly (24:1), 2000, pp. 115-139.

Wajcman, J. Feminism Confronts Technology, Cambridge, England: Polity Press, 1991.

Wajcman, J. "Reflections on Gender and Technology Studies. In What State Is the Art?" Social Studies of Science (30:3), 200, pp. 447-464.

Webster, J. Shaping Women's Work: Gender, Employment and Information Technology, London: Longmans, 1996.

Wilson, M., Howcroft, D. "The Role of Gender in User Resistance and IS Failure," in Organizational and Social Perspectives on Information Technology, R. Baskerville, J. Stage, and J. I. DeGross (eds.), Boston: Kluwer Academic Publishers, 2000, pp. 453-472.

\section{About the Authors}

Alison Adam joined the University of Salford in 2000 having previously worked in the software industry, at the University of Lancaster, and at UMIST. Her research interests are computer ethics and gender and information technology. Her book, Artificial Knowing: Gender and the Thinking Machine, was published by Routledge in 1998. Alison can be reached by e-mail at A.Adam@salford.ac.uk.

Helen Richardson joined the University of Salford in 1998 and has initiated a number of research activities in the field of business-to-consumer e-commerce, teaching and e-learning, and gender issues in IS research. Previously, Helen worked as a manager in the field of social and community work and ran a research and training unit promoting positive action for women at work before teaching for over 10 years in the Further and Higher Education sector. Helen can be reached by e-mail at H.Richardson@salford.ac.uk. 
Debra Howcroft is a lecturer at the IS Institute and Deputy Director of the IS Research Centre. She has a mixture of both industrial and academic experience which includes four years as a systems developer. Her research interests broadly lie in the area of the social and organizational aspects of the development, implementation, and use of ICTs. Debra can be reached by e-mail at D.A.Howcroft@salford.ac.uk. 